EPiC Series in Education Science
Volume 3, 2020, Pages 98-107
Proceedings of the MIT LINC 2019 Conference

\title{
Changing the state of literacy in the Digital Age in India
}

\author{
Aanandita Gahlot ${ }^{1 *}$ and Shubhankar Gahlot ${ }^{2 \dagger}$ \\ ${ }^{1}$ USME, Delhi Technological University, India \\ ${ }^{2}$ Illinois Institute of Technology, Chicago, U.S.A. \\ aananditagahlot@gmail.com, sgahlot@hawk.iit.edu
}

\begin{abstract}
India as an emerging economy deals with troubles in literacy due to factors like shortage of quality academic institutions and unsuitable curriculum. Digital Technology is accredited as something which can bridge the gap between quality institutions and individuals and make learning more engaging.

Indian Government has made use of technology in the best possible way and launched Pradhan Mantri Gramin Digital Saksharta Abhiyan (PMGDISHA) $\$$ under its Digital India initiative. It has been initiated to make at least one individual from each household digitally literate so that they develop the skills which will be needed to link with the rapidly growing digital world. This scheme aims to target the rural population including the disparaged sections of society like minorities, Below Poverty Line (BPL), women and differently-abled people.

The use of technology in education has transmuted the whole system of education. This paper is aimed at exploring the changing state of literacy in India after introducing PMGDISHA.
\end{abstract}

\section{Introduction}

India being the second most populous country is also the youngest country in the world with $65 \%$ of the population below the age of 35 [1]. This means that there are more than 800 million people, getting ready as a workforce who will not only change the course of India but also the world. The major challenge which India faces is to provide a quality education to this emerging workforce. This can only be achieved by providing them a resourceful education that is not only enough to skill them but also enables them to contribute to the development of the society.

The pyramid of population density in Fig. 1 indicates the pattern of age distribution in India. The curve for India is highly voluminous till the age of 25 and then it tapers smoothly. United States has 
almost constant age distribution while China's Population curve is contorted due to its one child policy. [1]

\footnotetext{
* Research, literature survey and writing the document

${ }^{\dagger}$ Mastermind and mentoring with the revisions of the document

† Prime Minister Rural Digital Literacy Mission
}

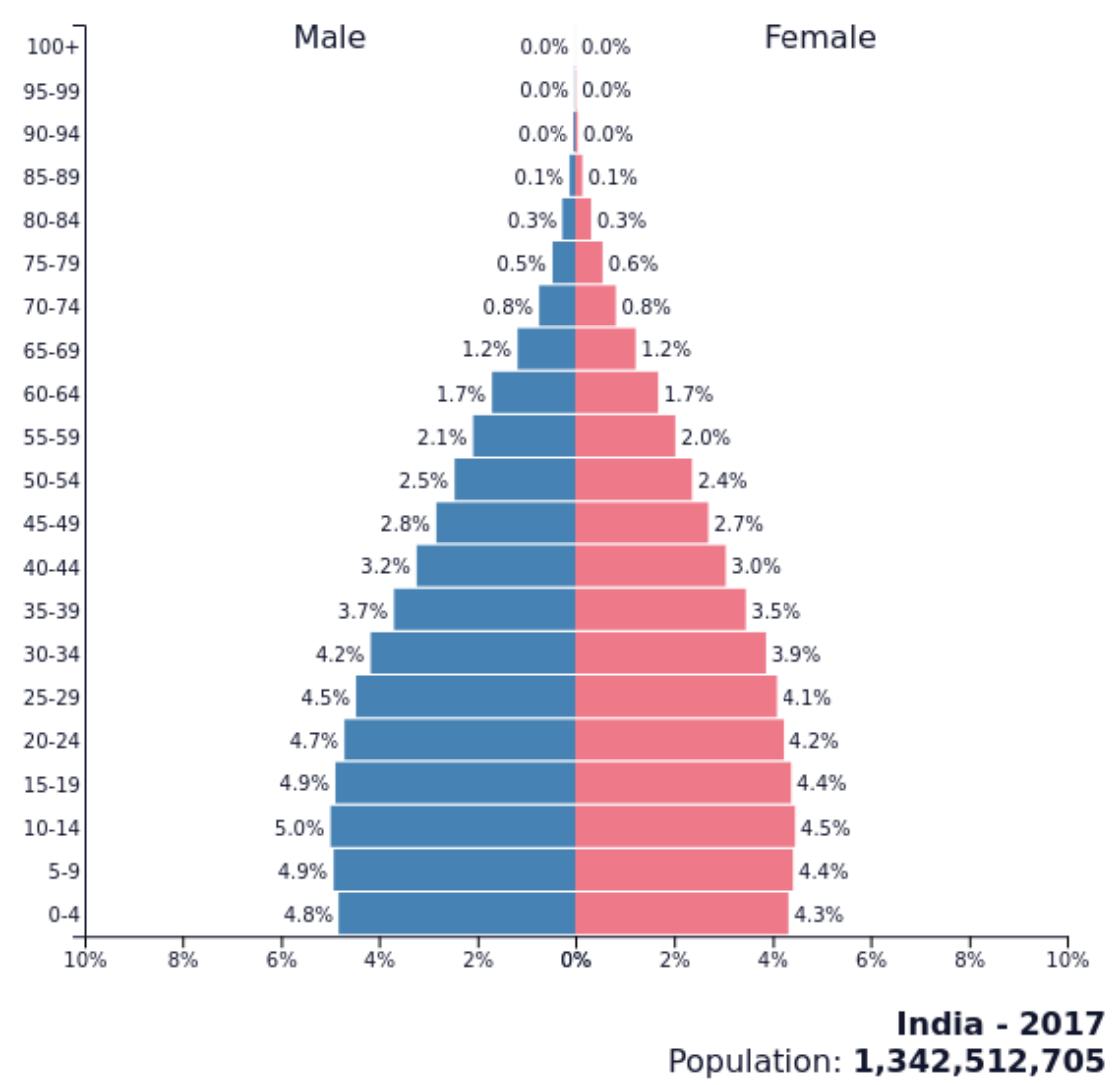

"Fig 1: Population density of India"

Fig. 1 evidently shows that India needs to strengthen its education system both at the policy as well as infrastructure level. The existing education infrastructure is insufficient for the growing demand of the emerging population and the only way to strengthen it is by leveraging digital technology and elearning. According to 2015 world bank data, India has nearly $81 \%$ and $63 \%$ literate males and females respectively [4]. On one hand, the major drawback in the long-term education is the unsustainable economic condition of the family that keeps a child away from pursuing education while on the other it is the lack of proper education infrastructure in sub-urban and rural areas.

Furthermore, regions with restricted accessibility, for example north east India which are home to 39 million people have literacy level of $68.5 \%$. The states of Assam and Arunachal Pradesh have literacy rate less than the national average. The land terrain, language barriers and other activities have prohibited easy access for people from these states into other states and vice-a-versa [3]. Other states 
also face the similar issues. But the advent of internet and other mobile technologies has opened new avenues for advancement. Mobile phone and internet penetration are rising rapidly with current mobile usage at $65-75 \%$ and internet usage at $40-50 \%$. It is estimated that mobile phone penetration and internet penetration will reach $85-90 \%$ and $45-50 \%$ respectively by 2020 [2].

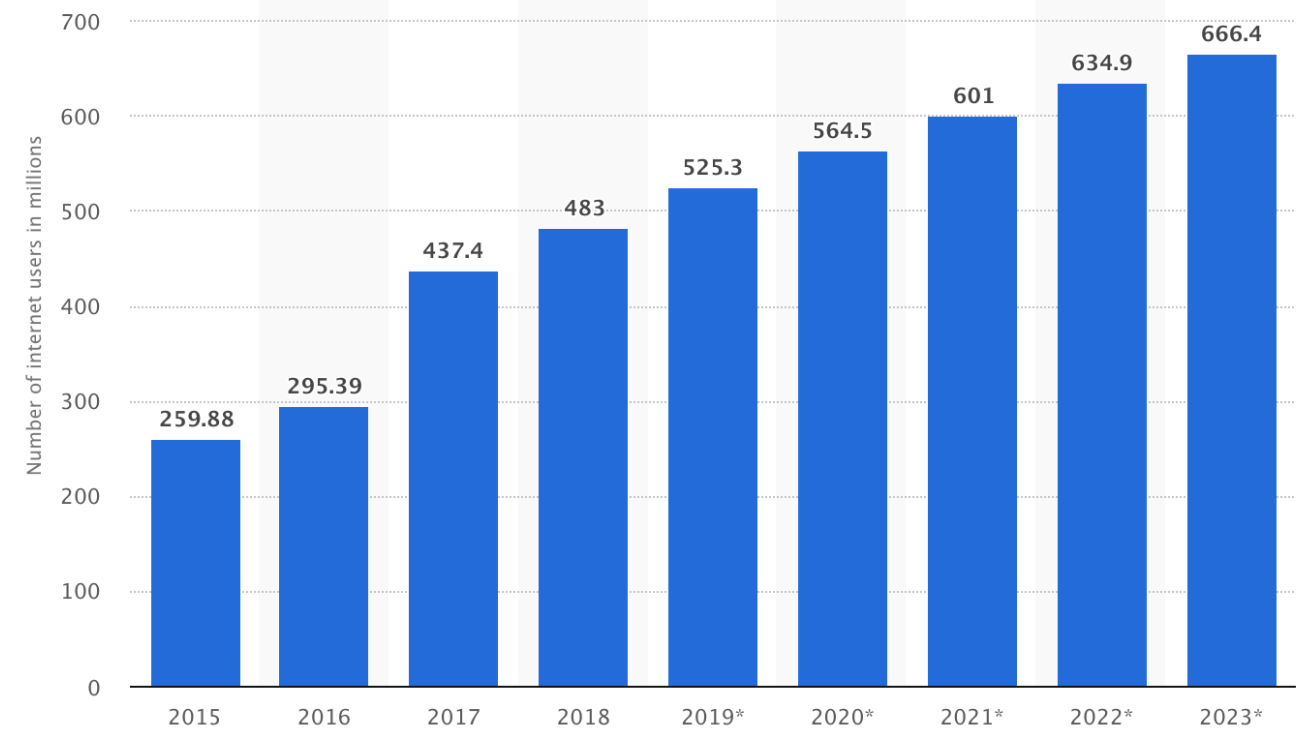

"Fig 2: Internet Users' growth in India [2]"

Fig. 3 clearly depicts that one out of every five people in India is illiterate. As more than $70 \%$ of the total population of India lives in rural areas, the status of literacy cannot improve without targeting them [4].

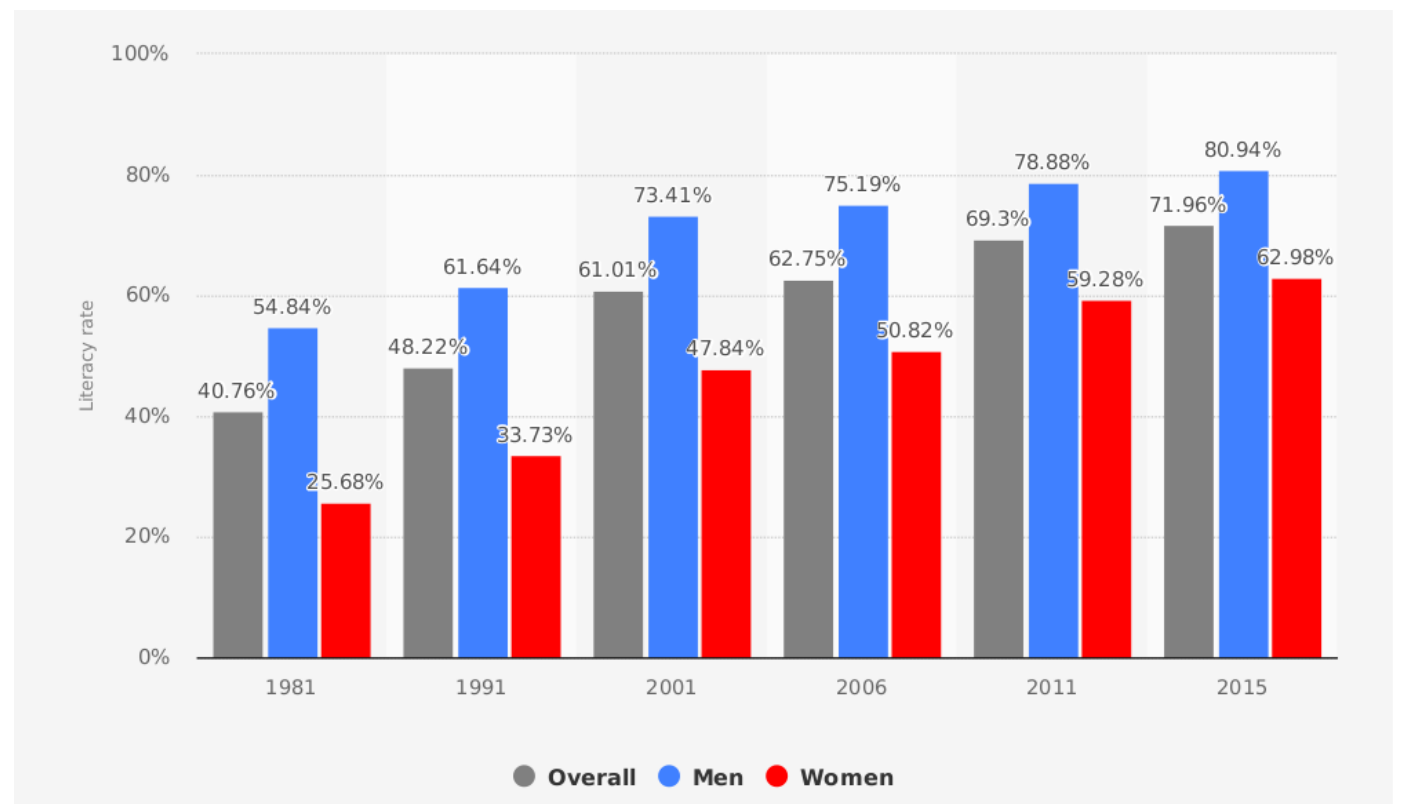

"Fig 3: Literacy in India from 1981-2015 [4]" 
It is estimated that by 2020 more than $50 \%$ of the world's illiterate will reside in India. This made the government to take an initiative to introduce a digital literacy program to help people leverage the ever-growing mobile and internet penetration. It is a mechanism through which education in the rural India can be influenced the most. This paved the way for launching Pradhan Mantri Gramin Digital Saksharta Abhiyan (PMGDISHA) program under its Digital India initiative for spreading digital literacy to the remote areas and underprivileged people.

The implications of the scheme have been phenomenal. Digital literacy mission has accelerated the literacy growth in India especially in the rural parts of the country, which is very evident from the correlation between growth in digital literacy and number of private as well as public MOOCs (Massive Open Online Courses) registrations.

\section{Education in rural India}

According to census 2011, India has a highly varied literacy rate. Kerala tops the list with $93.9 \%$ literacy rate and while Bihar has least literacy rate of $63.8 \%$. Rural areas report a literacy rate of $68.9 \%$ and the urban areas register $85.0 \%$ literacy, resulting in an absolute difference of nearly 16 percentage points [5]. One of the main factors contributing to this relatively low literacy rate is shortage of school infrastructure to accommodate all the students. Also, the average pupil teacher ratio for all India is 42:1, implying a teacher shortage [13].

The condition becomes even worse if we take literacy in rural India into account as seen from the table below. 
"Table 1: States with the Lowest Rural Literacy Rate [5]"

\begin{tabular}{|c|c|c|c|}
\hline States & $\begin{array}{c}\text { Literacy Rate in } \\
\text { Rural (\%) }\end{array}$ & $\begin{array}{c}\text { Literacy rate in } \\
\text { Urban (\%) }\end{array}$ & Total Literacy (\%) \\
\hline Rajasthan & 62.3 & 80.7 & 67.1 \\
\hline Jharkhand & 62.4 & 83.3 & 67.6 \\
\hline Bihar & 61.8 & 71.8 & 63.8 \\
\hline Andhra Pradesh & 61.1 & 80.5 & 67.7 \\
\hline Arunachal Pradesh & 61.6 & 82.9 & 67.0 \\
\hline
\end{tabular}

The problems that India faces can be summarized as follows:

1. Large emerging youth population. [Ref Fig: 1]

2. Low literacy rate [Ref Fig: 3]

3. Huge rural population

4. Inadequate public infrastructure in rural areas.

5. Low literacy rate among women specifically, in rural areas. [Ref Table: 1]

6. Lack of proper educational infrastructure.

7. Lack of adequate number of qualified instructors. [7]

Policy intervention is needed in order to solve these problems so that it could impact a large number of people in a very small-time span. This is where government launched the PMGDISHA program under Digital India initiative.

\section{PMGDISHA (Pradhan Mantri Gramin Digital Saksharta Abhiyan)}

PMGDISHA is a scheme under NDLM (National Digital Literacy Mission) initiative of Digital India campaign which was launched in August 2014 by the government of India. Following the successful implementation of NDLM schemes, PMGDISHA was approved by the government in February 2017. The curriculum for the program was developed in 2014 in consultation with various agencies like UNESCO, National Association of Software and Services Companies (NASSCOM), Intel, Indira Gandhi National Open University (IGNOU), National Institute of Electronics \& Information Technology (NIELIT), National Institute of Open Schooling (NIOS), Indian Institute of Mass Communication (IIMC), IT for Change, Open Knowledge Network India, and Digital Empowerment Foundation.

\subsection{Objectives}

The main objective of the program is to make six million people in rural areas, across States/UTs, by March 2019 digitally literate, reaching to around $40 \%$ of rural households by covering one member 
from every eligible household. The Scheme is aimed at empowering the citizens in rural areas by training them to operate computer or digital access devices (like tablets, smart phones etc.), send and receive emails, browse the Internet, access Government services, search for information, undertake digital payment, etc. and hence enable them to use the Information Technology and related applications especially Digital Payments to actively participate in the process of nation building. Thus, the Scheme aims to bridge the digital divide, specifically targeting the rural population including the marginalized sections of society like Scheduled Castes (SC) / Scheduled Tribes (ST), Below Poverty Line (BPL), women, differently-abled persons and minorities. The ultimate aim is to cover the gap between the rural and urban youth.

\subsection{Implementation}

The Scheme is implemented by using the affiliated Training Partners/Training Centers. Training Partners/Training Centers are assigned with a specified area of operation and target preferably within the same state. The Training Partners/Training Centers need to have basic facilities to conduct the training as per the accreditation norms prescribed by CSC-SPV (CSC e-Governance Services India Limited, a Special Purpose Vehicle incorporated under the Companies Act 1956).

These would include Common Service Centers (CSC), National Institute of Electronics \& Information Technology (NIELIT) Centers or its accredited Centers, Adult Literacy Centers or schools implementing Information and Communication Technology (ICT@schools) scheme under the Ministry of Human Resources and Development (MHRD), Indira Gandhi National Open University (IGNOU) centers, NGOs involved in IT literacy, Rural Self-Employment Training Institutes, Industry partners, companies with CSR provisions, etc.

The eligible age of enrollment is 14-60 years. The duration of the course is 20 hours and it is delivered in all official languages of India. Candidates are evaluated by a national level certifying agency [14].

\subsection{Training Fee}

The candidate pays no training fee.

\subsection{Registration Status}

By the end of August 2018, 12,343,083 beneficiaries have been registered under the project and out of which 12,321,098 beneficiaries have completed training from all the States/UTs. [8] 
“Table 2: Status of top 5 states as of Jan'18 [9]"

\begin{tabular}{|c|c|c|c|c|c|}
\hline S.No. & State & Targets & $\begin{array}{c}\text { Candidates } \\
\text { Registered }\end{array}$ & $\begin{array}{c}\text { Training } \\
\text { Completed }\end{array}$ & $\begin{array}{c}\text { Certified } \\
\text { Candidates }\end{array}$ \\
\hline 1. & UTTAR PRADESH & 11171000 & 2432262 & 2390272 & 1131112 \\
\hline 2. & BIHAR & 6630000 & 747778 & 736956 & 373082 \\
\hline 3. & WEST BENGAL & 4481000 & 280368 & 272757 & 124586 \\
\hline 4. & $\begin{array}{c}\text { MAHARASHTRA } \\
\text { AND GOA }\end{array}$ & 4433000 & 493103 & 482997 & 248473 \\
\hline 5. & $\begin{array}{c}\text { MADHYA } \\
\text { PRADESH }\end{array}$ & 3784000 & 704085 & 686995 & 332535 \\
\hline
\end{tabular}

\subsection{Examination Status}

PMGDISHA examination is conducted across the country and stringent with biometric authentication of candidates by an Invigilator/Exam Superintendent. As of January 2018, a total of 5,329,989 candidates have been certified under the scheme [9]. The gender wise distribution among the certified candidates under PMGDISHA is almost equal, with 53\% males and 47\% females [8].

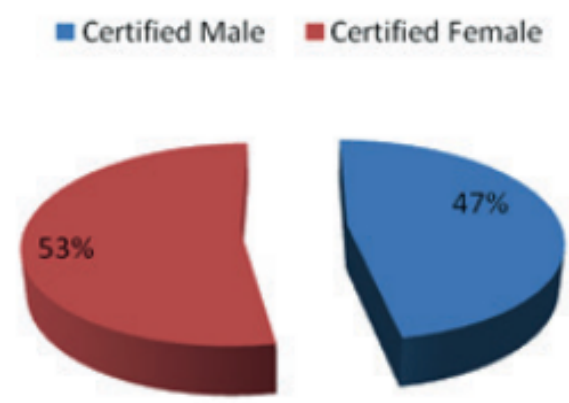

"Fig 4: Gender wise distribution of certified candidates [8]"

\section{Impact on Massive Open Online Courses (MOOCs)}

Internet has disrupted all industries including the education industry by exponentially reducing infrastructure and operational costs. Therefore, online education has become a lucrative business and Massive Open Online Courses (MOOC) like Coursera, Udacity, Udemy, Edx, etc. are an outcome of this disruption. But in order to be part of this disruption one has to be digitally literate. That is where initiatives like PMGDISHA help make people digital ready. 
As per 2016 statistics shared by Coursera there were 13 lakh online learners from India as compared to the total 180 lakh online learners on Coursera. There had been a $70 \%$ jump in the enrolment of courses by Indians. Edx, which is another MOOC platform, in 2017 has also announced $73 \%$ growth in the Indian market over the past year. In India Coursera is growing faster than the global average, with about 2 million Indian learners enrolled in various courses, ranging from a few weeks to two years. Even Indian government has built its own MOOC platform known as SWAYAM to leverage this digital wave [10] [11] [12].

By year 2030, the Indian government aims to increase the Gross Enrolment Ratio (GER) in universities to $30 \%$ from $23 \%$ in $2014-15$. And this will practically not be possible by just setting up more traditional classrooms \& universities.

Therefore, it's very well evident from the data that this digital literacy initiative is driving the MOOC industry in India and will keep doing so in the coming future. We will also see a greater number of people learning from these non-traditional sources as well.

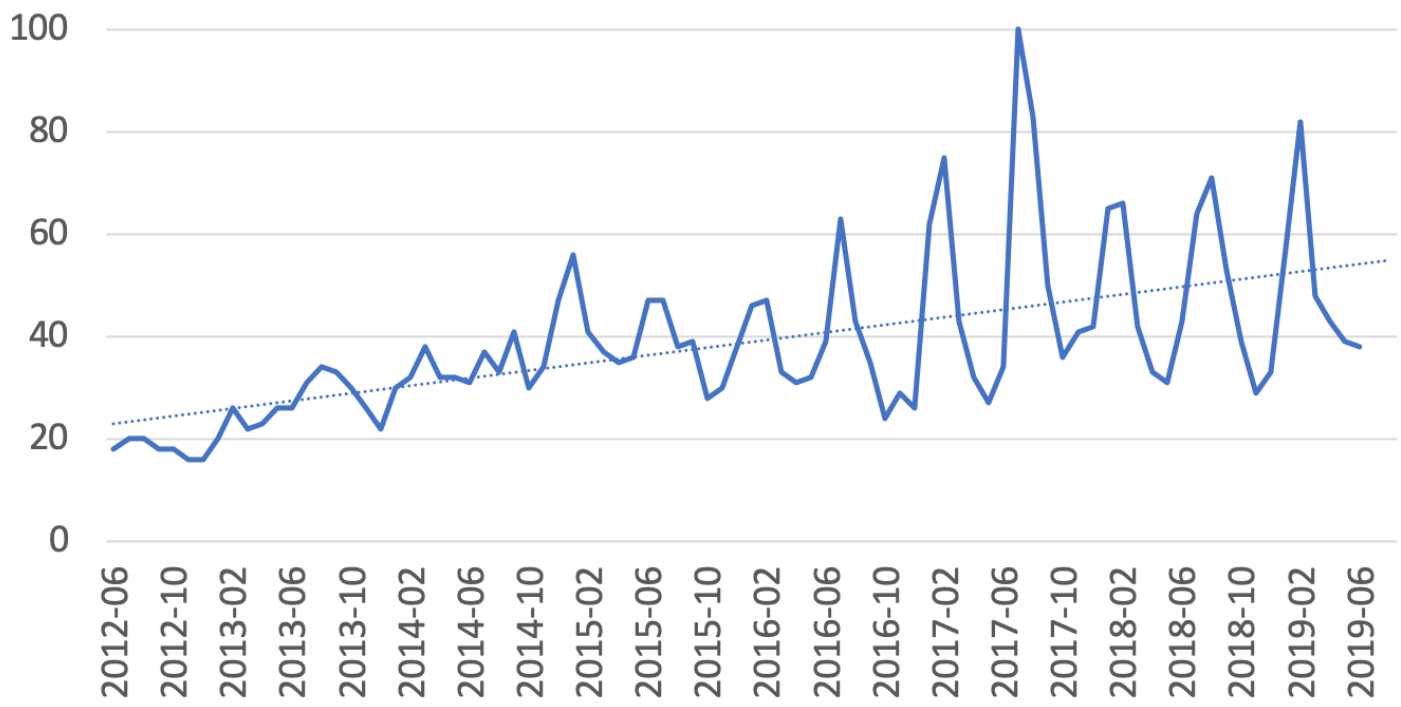

“Fig 5: Google Trends' results for Massive Open Online Course (topic) [15]"

In fig. 5, the numbers on the vertical axis represents the search interest relative to the highest point on the chart and horizontal axis represents the time period. A value of 100 is the peak popularity for the term which is attained in the second half of the year 2017.

Trend line shows a rapid increase in the number of google searches for the topic MOOC which can be attributed to increase in the internet penetration and growing digital literacy.

\section{Conclusion}

The best way to raise the standard of education and improve literacy in a country is to make its citizens digitally literate as early as possible so that they can utilize the available digital tools and technologies. This policy-based solution by government of India can become an inspiration for other 
countries to learn from and help them to raise their education standards. A small investment by the government of India in digital education of its citizens has proved to be a huge stepping stone in making its people self-reliant in educating themselves. Through this paper we have tried to explain how digital literacy can change the whole education scenario. The initiative has proved to be beneficial for all sections of the society. Due to its overwhelming success we expect other countries to follow suit and launch such initiatives to educate their citizens.

\section{References}

[1] https://www.populationpyramid.net

[2] https://www.statista.com/statistics/255146/number-of-internet-users-in-india/

[3] http://ijmra.us/project\%20doc/2018/IJRSS_NOVEMBER2018/IJMRA-14646.pdf

[4] https://www.moneycontrol.com/news/business/economy/data-story-this-international-literacy-daylets-recap-indias-literacy-growth-2382359.html

[5] http://censusmp.nic.in/censusmp/All-PDF/6Literacy21.12.pdf

[6] https://www.mapsofindia.com/my-india/society/low-female-literacy-rate-and-its-impact-on-oursociety

[7] Vikram Desai, Jagdish Murthy, Ravi Saksena, Ajay Gupta, Enhancement of primary education using EDUSAT: Rajiv Gandhi project for EDUSAT supported elementary education network (RGPEEE) overview, Acta Astronautica, Volume 65, Issues 9-10, November-December 2009, Pages 1440-1445, ISSN 0094-5765, 10.1016/j.actaastro.2009.03.086.

(http://www.sciencedirect.com/science/article/pii/S0094576509002227)

[8] https://www.pmgdisha.in/wp-content/uploads/2018/10/PMGDISHA-booklet-August.pdf

[9]

https://digitalindia.gov.in/writereaddata/files/PMGDISHA_Ministrial\%20Conclave\%20Revised.pdf

[10] “Coursera's second largest market-India”, https://yourstory.com/2017/04/coursera-nikhil-sinha/

[11] "Online learners in India will grow by leaps \& bounds", http://www.indiaeducation.net/onlineeducation/articles/5-online-education-trends-to-watch-in-india.html

[12] https://www.indiainfoline.com/article/b-school-news/edx-marks-a-73-growth-in-india-in-oneyear-

117020100304_1.html 
[13] https://data.gov.in/catalog/pupil-teacher-ratio-ptr

[14] https://graminshiksha.com/Projects/Pradhan-Mantri-Gramin-Digital-Shaksharta-MissionFranchise-10-44

[15] https://trends.google.com/trends/explore?date=today $\% 205-\mathrm{y} \& g e o=I N \&$ q=\%2Fm $\% 2 F 0$ gyvy 46 